\title{
Belphégor
}

\section{Le pas suspendu de la modernité : Le passage de la culture populaire à une culture de masse dans l'Europe de Sud-Est}

Lampros Flitouris et Christos Dermentzopoulos

\section{(2) OpenEdition}

Journals

Édition électronique

URL : https://journals.openedition.org/belphegor/2426

DOI : 10.4000/belphegor.2426

ISSN : 1499-7185

Éditeur

LPCM

Référence électronique

Lampros Flitouris et Christos Dermentzopoulos, «Le pas suspendu de la modernité : Le passage de la culture populaire à une culture de masse dans l'Europe de Sud-Est », Belphégor [En ligne], 18-1 | 2020, mis en ligne le 04 mars 2020, consulté le 29 juin 2021. URL : http://journals.openedition.org/ belphegor/2426 ; DOI : https://doi.org/10.4000/belphegor.2426

Ce document a été généré automatiquement le 29 juin 2021.

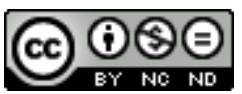

Belphégor est mis à disposition selon les termes de la Licence Creative Commons Attribution - Pas d'Utilisation Commerciale - Pas de Modification 4.0 International. 


\title{
Le pas suspendu de la modernité : Le passage de la culture populaire à une culture de masse dans l'Europe de Sud-Est
}

\author{
Lampros Flitouris et Christos Dermentzopoulos
}

Qu'est-ce que la culture folklorique, la culture populaire et la culture pop? Pourquoi parler, pour une région de l'Europe, du passage d'une culture folklorique ou populaire à une culture de masse? Les analyses suivantes peuvent être lues comme une tentative de définition. D'après Maurice Louis la culture folklorique concerne la « connaissance qu'on a des choses du peuple ", c'est-à-dire de toutes les formes de manifestations populaires telles que légendes, contes, bouffonneries, récits, chants populaires, musiques et danses populaires, énigme, boutade, etc. qui existent sous la forme de coutume orale, se transmettant encore de bouche à oreille en tant que tradition du présent vécu. ${ }^{1}$ Le folklore étudie une société contemporaine et s'intéresse à des formes anciennes de sa culture mais qui ont déjà disparu ou régressent face à la modernisation. ${ }^{2}$ La culture populaire, comme lien entre les générations, est le facteur d'intégration et d'exposition de l'altérité, ainsi qu'un facteur fondamental de l'identité, de l'unité du groupe et de sa continuité. La culture pop est un phénomène mondial associé à des attributs tels que la liberté ou la subversion. Facilement accessible à de larges parties de la population, elle offre des modes de vie qui peuvent être adoptés ou adaptés de manière informelle. La culture pop embrasse différents styles de musique, des arts de la scène, du cinéma, des modes de vie, de la mode, de la littérature et même du sport. Ainsi, la culture pop a un lien très fort avec les expériences quotidiennes des gens. Elle a connu un progrès rapide et a pris des dimensions mondiales et massives après les années 1940 à travers un processus de transfert culturel. Elle ne s'arrête pas devant le rideau de fer pendant la guerre froide, mais atteint le bloc de l'Est en temps réel. ${ }^{3}$ Comme Umberto Eco a montré avec "le mythe de Superman" ou l'influence jamesbondienne ${ }^{4}$, cette interaction entre les cultures fut un phénomène universel d'après-guerre qui a touché également l'Europe de l'Est et du Sud-Est. 
2 Le présent article fait partie d'une recherche en cours sur la transition des sociétés de l'Europe du Sud-Est: celle-ci se traduit par l'institutionnalisation de la culture folklorique ou populaire de la fin du XIXe siècle aux années 1940 pour la formation d'une culture nationale. ${ }^{5}$ Ce point appelle une précision. Dans les pays balkaniques, la notion de culture de masse correspond à la transformation des sociétés examinées après la guerre et notamment après les années 1950 et 1960. Pendant cette période, l'évolution de la culture populaire et la consommation de ses produits n'étaient pas les mêmes pour les sociétés de la région. Dans le cas grec, la recherche scientifique s'occupa notamment de la période de la fin du XIXè siècle, des deux premières décennies du XXè siècle et de l'apparition de la «paralittérature $" .{ }^{6}$ Après la Seconde Guerre mondiale, les pays du bloc occidental tels que la Grèce et la Turquie et jusqu'à un certain point le cas yougoslave présentent une transition de leur passé folklorique vers une période de naissance d'une culture populaire dans les années 1930 (presse et revues populaires, roman populaire et traduction des fictions de mystère, polar ou science-fiction dans les langues locales, apparition d'une production locale de paralittérature et de presse populaire, etc.) A partir des années d'après-guerre, on assiste à une certaine " américanisation » des habitudes culturelles, au développement d'une nouvelle clientèle (et des producteurs) des produits culturels de masse (musique occidentale, mode, cinéma, presse pour la jeunesse, B.D. etc.). Les jeunesses de ces pays deviennent un facteur crucial de la nouvelle orientation culturelle. Ces remarques devraient être examinées en parallèle avec les conditions particulières de chaque pays et par rapport au passé culturel de l'avant-guerre. La Yougoslavie et la Grèce avaient déjà un certain passé de production populaire du type occidental qui essayait de combiner la tradition à la modernité. Le cas du roman de bandits en Grèce et les influences de la fiction européenne nous en offrent un exemple caractéristique. ${ }^{7}$

3 Les autres pays de la péninsule, sous influence soviétique après 1945, se trouvent pendant la même période dans une situation encore plus délicate. En Bulgarie et en Albanie les influences culturelles et artistiques de l'Occident (de la France pour les deux, de l'Allemagne pour la Bulgarie et de l'Italie pour l'Albanie) sont restées au niveau de la culture dite sérieuse et semi-officielle. L'urbanisation tardive dans ces pays, l'absence d'une véritable et forte bourgeoisie et le sous-développement des médias avant la guerre forment les limites de l'activité culturelle et populaire.

4 L'arrivée au pouvoir des communistes en 1945 marqua la nature de ce passage vers la modernité, avec l'incorporation du folklore à l'idée de la culture nationale et avec la reconnaissance de la culture populaire (dite folklorique) comme aspect de la vie culturelle des pays. La notion de masse resta dans le cadre du réalisme socialiste et elle eut pour but essentiel la propagande du régime auprès des masses avec l'utilisation de canaux similaires à ceux que la culture-pop utilisait en Occident.

5 En Grèce, la première période qui mérite d'être examinée dans ce cadre est celle qui s'étend va de 1927 à 1935, c'est-à-dire pendant la Deuxième République grecque et l'explosion de l'urbanisation dans le pays, résultat notamment de l'arrivée des réfugiés grecs de l'Asie Mineure des années 1920. Les changements socioculturels dans les grandes villes grecques ont influencé la nature du roman populaire et en général la production de ce genre (presse, théâtre populaire, développement d'un réseau des salles cinématographiques etc.). L'augmentation du public lettré, l'apparition des revues hebdomadaires ainsi qu'une certaine nécessité d'« occidentalisation » du pays sont des raisons qui expliquent le renforcement de la culture populaire urbaine et une 
médiatisation de base avant la deuxième période de censure, imposée par le régime de Metaxás après $1936 .^{8}$ Même pendant cette période, l'influence de la culture occidentale reste très présente : par exemple un des écrivains de fiction criminelle connus, le poète Georges Tsoukalas, alias Georges Pottier, publia des titres policiers (Les mystères de Chicago, Le Fantôme rouge etc.). Sous son vrai nom, il continua la tradition du roman de bandits mais avec un héros gigantesque, immortel, portant un masque et le costume traditionnel grec : son nom est «Capitan Apethantos (Immortel)»! C'est la période de forte influence de la fiction américaine et anglaise avec l'apparition des histoires de vampires, de personnages immortels ou invisibles. ${ }^{9}$ Pourtant les périodes de la guerre de 1940-1944 et de la guerre civile de 1946 à 1949 ont bloqué cette évolution. Bien évidemment le fait que la Grèce se trouva dans le camp occidental explique le phénomène de la présence d'une culture de masse dans les deux décennies qui suivent.

6 Après la guerre, les Américains et les Britanniques ont pris conscience de l'importance que pourrait avoir la formation de citoyens anglophiles, surtout dans les pays qui étaient sous leur emprise. Ils ont d'abord mis en œuvre les conditions qui leur seraient nécessaires pour répandre leur langue. En imitant l'expérience française d'avantguerre, ils ont fondé des instituts et des collèges qui, grâce aux généreuses subventions publiques et privées, couvriront tout le territoire grec. Ce phénomène ne concerne pas exclusivement la Grèce, mais il est très courant en Europe et il s'explique par la transition progressive des marchés locaux vers le marché universel, sous contrôle américain. L'économie et surtout le mode de vie américain contribuèrent à l'expansion de la culture associée à ce pays. Les nouveaux moyens de distraction et d'information le cinéma, la radio et un peu plus tard la télévision - transmettent l'image d'un Nouveau Monde idéal dans la vieille Europe ruinée par la guerre, une image qui ne peut qu'être très attractive. Pour la formation d'un réservoir « of good will » à l'égard des Etats-Unis et d'un groupe de "modeleurs d'opinion" (opinion molders), ils ont utilisé des organisations de jeunesse telles que la YMCA, les scouts, etc. À côté des formes classiques de pénétration, les Américains ont utilisé pour la première fois aussi largement d'autres moyens de propagande plus efficaces. Les émissions radiophoniques de Voice of America (fondée en 1942) et les stations de radio des bases militaires américaines à Athènes et en Crète ont permis à la jeunesse hellénique d'accueillir les produits de la pop-culture venus des Etats-Unis. ${ }^{10}$ Jusqu'aux années 1970, les radios américaines resteront le moyen le plus efficace pour les jeunes du pays de découvrir les nouvelles vagues de la musique, du cinéma et de la mode. De même, l'ouverture des centres d'information par les services américains partout en Grèce a permis la promotion du film américain. Comme dans toute l'Europe, les États-Unis ont fourni les distributeurs en milliers de films à bas prix. Des films de propagande anticommuniste, des documentaires sur les activités pacifiques de la Mission Américaine, sur la vie des immigrés grecs aux Etats-Unis et sur la vie quotidienne outre-Atlantique ont formé une certaine idée du nouveau grand protecteur. Les salles d'informations américaines ont donné la possibilité même aux villageois les plus éloignés de voir l'image la plus belle du «monde libre». La politique globale des Américains dans le domaine de la promotion du mythe de Hollywood a eu pour résultat en Grèce, comme ailleurs, l'invasion totale du marché cinématographique par les produits américains. ${ }^{11}$

7 Le résultat de cette invasion du modèle de la culture de masse fut la formation d'une production locale inspirée par lui. Des revues et des périodiques qui imitaient les tendances de l'Occident, le sport et notamment le football, deviennent un spectacle pour les masses avec une couverture médiatique sans précédent; le cinéma populaire 
grec entre dans sa période de gloire, les traductions des polars américains (mais aussi européennes) et l'apparition du photo-roman venu d'Italie dominent la culture pop des années d'après-guerre; cette situation, inédite pour le pays, présente des différences significatives avec ce qui se passe dans les pays voisins.

La Turquie montre une tendance similaire, notamment après les années 1940. A Istanbul surtout, on peut pratiquement parler d'une explosion de la culture de masse et d'une modernisation des formes traditionnelles de la culture populaire de la période des sultans. Dans ce pays où la laïcité devient le dogme officiel de Kemal, et malgré le conservatisme qui domine les esprits, les importations de l'Occident prennent un caractère plus oriental pour pouvoir séduire une clientèle large mais pas forcément alphabétisée. Le roman-photo, la chanson et le cinéma populaire sont les domaines les plus développés de cette culture de masse. Celle-ci touchera de plus en plus les Turcs qui quittent l'Anatolie pour les grandes villes des côtes, caractérisées par l'occidentalisation des mœurs et des mentalités. Dans les années 1950 et 1960 et malgré les perturbations de la vie politique ou la crise de l'immigration, la scène turque de la culture médiatique présente des caractéristiques très impressionnantes, surtout parce que la société du pays reste à majorité rurale, musulmane et non-alphabétisée. Le marché de la musique populaire progressivement modernisé ou celui du du cinéma étaient développés avec des tendances d'exportation des produits vers le monde arabe ou même la Grèce et les Balkans communistes. Les comics européens et les fictions populaires de l'Occident font leur apparition (on trouve même même des versions turques en bandes dessinées et en films de Fantômas) ${ }^{12}$. La Turquie montre une orientation vers la modernité et la culture de masse qui s'explique aussi par la division du pays : d'une part la partie orientale et majoritairement peuplée se trouve de 1923 aux années 1960 encore sous l'influence du passé ottoman; d'autre part la partie des grandes villes de l'Ouest où le cosmopolitisme, la laïcité et l'évolution des habitudes consommatrices donnent la possibilité à la culture de masse de se développer.

Dans le cas des autres pays balkaniques, le pas vers la modernité avec le passage de la culture populaire à la culture de masse n'a pas été fait. Même en Yougoslavie ou en Roumanie, où les influences européennes (notamment françaises) étaient importantes, où le taux d'urbanisation, l'existence d'une certaine clientèle qui consommait les produits culturels de l'Occident et l'apparition dans les années 1920 et 1930 des revues, des éditions de fiction populaire - originales ou de traduction - étaient également significatives, l'utilisation du terme culture de masse ne se justifient pas. Les canaux pour l'évolution d'une culture de masse n'étaient pas encore formés quand la Seconde Guerre mondiale éclate. L'établissement des régimes communistes après 1945 a défini les limites de cette production de masse. Sur ce point, on doit de nouveau distinguer la notion de culture de masse de celle de culture socialiste (affiches, revues, manifestations et festivités massives, etc.) qui avait pour objectif de renforcer l'image du régime parmi les masses.

En Albanie du milieu du XIX ${ }^{e}$ siècle à la formation de l'Etat en 1912, la production de livres en albanais, diffusés dans l'Empire ottoman, a connu trois périodes : jusqu'au début du XIX ${ }^{e}$ siècle quelques rares ouvrages religieux furent publiés pour un public restreint ; les trois premiers quarts du XIX ${ }^{\mathrm{e}}$ siècle peuvent être considérés comme une période de transition, correspondant au passage du livre « sacré » au livre «national »; ce dernier se développe pendant la troisième période, entre 1878 et 1908 . L'indépendance a permis la formation d'une certaine classe bourgeoise qui resta très 
divisée jusqu'à l'occupation italienne dans les années 1930. L'Albanie d'entre-deuxguerres reste majoritairement rurale et à la recherche d'une vraie vie culturelle nationale, comme une étape nécessaire pour le renforcement de son identité nationale. La diffusion de la littérature s'accrut, mais avec de plus en plus de difficultés : il y a à cela des raisons externes (comme la censure) mais aussi des causes internes, telles que les importantes disparités religieuses, culturelles et régionales au sein de la population albanaise. Orientées vers l'Italie notamment, les classes bourgeoises du pays restent pendant cette période consommatrices de la haute culture et se nourrissent de revues ou de romans populaires italiens, A cette époque, il n'existe en Albanie ni les conditions pour une culture populaire à l'occidentale ni une clientèle importante dans les villes qui pourrait s'intéresser à une telle proposition culturelle. Jusqu'à la Seconde Guerre mondiale, on n'assiste pas à l'émergence d'une production locale de culture de masse (romans de fiction populaire, revues etc.). D'après les analyses effectuées sur le cas albanais, le rôle de la langue fut très important : la langue albanaise comptait à cette période plusieurs écritures et le taux d'Albanais lettrés était très restreint. D’ailleurs, l'adoption d'un alphabet unique fut très tourmentée. L'occupation italienne et l'annexion du pays à l'empire mussolinien, la guerre et l'établissement du régime Hoxha de 1944 au début des années 1990 n'ont pas permis l'évolution de la vie culturelle du pays. Découplée des évolutions non seulement de l'Occident, mais aussi du monde communiste, l'Albanie resta un cas à part où la culture de masse concernait exclusivement la propagande orchestrée par le gouvernement. ${ }^{13}$

Dans le cas yougoslave, le passage de la période de la culture populaire à la culture de masse est spécifique. Le fait que la tradition de la culture populaire serbe et croate était très forte et très présente dans la formation des identités nationales pendant le XIXe siècle est un des éléments qu'il faut souligner dans notre analyse. Dans les grandes villes du royaume des Serbes, seule Belgrade a connu le développement de revues et d'une presse à grand tirage. De l'autre côté du Danube, la Croatie et la Slovénie, dominées par les Autrichiens et influencées par la culture italienne, ont présenté une vie culturelle qui prenait ses distances avec la tradition et qui s'orientait vers l'Occident. Les cafés de Ljubljana et de Zagreb sont devenus les ateliers des avantgardistes. ${ }^{14}$ Jules Verne sera le premier auteur populaire traduit en serbo-croate en 1873. En 1889 dans la revue populaire Kolo Dragutin Ilic a publié le premier drame de science-fiction créé dans le pays. Peu après, au début du XXème siècle, certains auteurs essayent de publier des histoires inspirées par la littérature occidentale, notamment dans les domaines des récits criminels et de science-fiction. C'est de la même période que date la première traduction d'un Fantômas en Croatie. Après la formation de la Yougoslavie unie en 1918 et jusqu'à la guerre, un nombre important de nouvelles a été publié dans les revues populaires sous pseudonymes (Kroz vasionu $i$ vekove ["Grâce à l'Univers et aux siècles »] (1928) de Milutin Milanković, Gospodin čovjek (1932) de Mate Hanžeković, et Život u vasioni [ « La vie dans l'Univers »] (1933) de Stojan Radonić). Dans les années 1930 un nombre important de fictions populaires a été publié par des revues qui avaient un lectorat étudiant et bourgeois. ("Atomska raketa» [ Une fusée atomique »] (1930), «Zrake smrti » [«Les Rayons de la Mort»] (1932) et "Smaragdni skarabej » ["Le Scarabée d'émeraude »] (1934)). En 1935 on assiste même à l'apparition des premiers comics en Yougoslavie (Gost iz svemira [«L'invité de l'espace»]), par Božidar Rašić et Leontije Bjelski. La formation de la République Populaire Fédérale par Tito en 1944 a changé, bien sûr, le cadre de cette activité populaire. ${ }^{15}$ La nature du titisme et le fait que le pays n'était pas hermétiquement fermé à l'Occident, de même 
que la tradition du roman populaire ont permis une activité culturelle qui a pris des dimensions plus massives dans les années 1950 et 1960 sans éviter les influences américaines ou européennes (notamment de l'Italie et de l'Allemagne). ${ }^{16}$ Dans les années 1950 ont paru les premières collections spécialisées en science-fiction telles que Biblioteka fantastičnih romana, Fantastični romani et Lajka - qui publiaient notamment des traductions des histoires soviétiques à l'exemple du réalisme socialiste. Dans les années 1960 des auteurs comme Zvonimir Furtinger ${ }^{17}$ et Mladen Bjažić écrivent des dizaines d' histoires, notamment de science-fiction, destinées aux adolescents (Osvajač 2 se ne javlja ["Conquérant 2 n'envoie pas de signal »] (1959) et Svemirska nevjesta ["La mariée de l'espace"] (1960). Pendant la même période la maison d'édition Kentaur a publié plus de 100 titres de romans populaires, américains et britanniques. Des revues en série comme Kosmoplov ["Spaceship"] ou Galaksija ["Galaxie"] ont marqué la période 1969-1978. C'est la période de l'expansion dans le pays de la musique rock n'roll, de la formation des groupes de musique moderne, de l'ouverture des premières boites de nuit, du printemps du cinéma populaire, de la modernité venue d'une télévision qui n'avait pas les ankyloses des autres télés des États socialistes. ${ }^{18}$

La Bulgarie représente un cas plus typique de la région. Avec une vie culturelle dominée par la tradition, et une société majoritairement rurale, le pays fut marqué par une période de vie politique instable, un retard économique et social dans les années 1920-1940 et la réalité d'un régime ultra-soviétique après 1945. Dans la période 1878-1945 les auteurs bulgares ne s'intéressent pas au développement d'une fiction urbaine et populaire..$^{19}$ Dans les années 1920, à l'image de la production en Grèce et en Yougoslavie, on assiste à l'apparition de premières histoires courtes de mystère et de science-fiction: Siniata Hrizantema ["Le chrysanthème Bleu»] (1921), Tshasovnik [«L'horloge »] (1924) et Ognena Ptitza [«L'Oiseau de Feu»] (1927). Les œuvres par exemple de Svetoslav Minkov ${ }^{20}$ sont très influencées par Edgar Allan Poe ou les auteurs allemands du fantastique de la même période. Georgi Iliev, l'auteur de O-Korse (1930) et Teut se Bountuva (1933) a été surnommé le père de la science-fiction bulgare. Ces efforts prometteurs n'eurent pas de suite à cause de la guerre et de la période stalinienne. Suivant le modèle soviétique des années 1950, la Bulgarie présenta une production de fiction pop dans les genres de la science-fiction, du fantastique et de l'espionnage. Les fictions de la science-fiction et du fantastique - peu étudiés par les spécialistes proposaient une vision du futur plus optimiste par rapport aux dystopies qui caractérisent assez souvent la production anglo-saxonne, et leurs sujets ne correspondaient pas au climat de la guerre froide de la période. Les héros, plus humains, s'engageaient dans la conquête de l'espace plutôt au nom de l'humanité qu'au nom des idéaux soviétiques (par exemple Zemiata Pred Gibel [«Terre au bord de la destruction »] (1957) de Tsvetan Angelov, Raketata ne Otgovaria [" Le missile ne répond pas »] (1958) de Dimitar Peev, Gushterat ot Ledovete ["Le lézard de la terre de glace »] (1958) de Petar Bobev et Atomniat Tshovek [«L'Homme Atomique »] (1958) de Ljuben Dilov). Dans les années 1960, Georgi Markov écrit Pobeditelite na Aiax [« Les Conquérants d'Ajax »] (1960), une space-opera. En 1962 fut inauguré un Club de science-fiction - une première pour le pays - ce qui témoigne de l'intérêt pour le genre. ${ }^{21}$ Les premiers efforts pour offrir une littérature policière datent de 1946. Sous les pseudonymes d'Edgar Rajno et de Conan Neznakom, Bogomil Rajnov (1919-2007) et Petăr Neznakomov (1920-1997) ont publié les premières parodies des fictions de détectives dans le quotidien humoristique Sturšel (Vespa). Rainov est devenu peu après le père du spy-novel bulgare. ${ }^{22}$ Sous la pression de la censure et des règles du réalisme socialiste, la 
solution de la parodie de polar était idéale. Pendant la même période, des auteurs bulgares expérimentaient les formes et les styles des maîtres occidentaux du genre mais la guerre froide a perturbé cette activité. Les années 1960 présentent un changement dans la culture populaire du pays. L'apparition en 1959 d'un vrai héros de pop culture nommé Avakum Zahov, créé par Andrej Guljaški (1914-1995), c'est-à-dire un agent de contre-espionnage mais qui ressemble plus à Sherlock Holmes qu'à James Bond, représente une phase importante dans l'incorporation des formes stylistiques de la culture populaire occidentale aux besoins du système socialiste. Zahov, figure solide, sophistiquée et avec un sens du sarcasme qui renvoie à Holmes, s'occupe d'un sabotage sur les frontières sud des pays de l'OTAN c'est-à-dire avec la Grèce et la Turquie. Protagoniste d'une série de livres extrêmement populaires en Europe de l'Est (mais également traduits en anglais en $1969^{23}$ ), Zahov fut aussi un héros transmédiatique avec l'apparition à la télé bulgare de la série populaire Les aventures de Avakum Zahov. Ce cas montre également qu'il y a parfois une certaine tolérance de la part des autorités des pays communistes des années 1960 et 1970 . Cette tolérance offre la possibilité d'une production de fictions populaires qui utilise les formes littéraires et artistiques du modèle occidental pour développer l'idée d'une guerre engagée contre la corruption, la décadence occidentale et les ennemis de la patrie socialiste.

\section{Conclusion}

13 Après l'examen d'une petite partie des productions des Balkans on peut dire que la région étudiée ne représente pas les caractéristiques de l'Occident ni avant ni après les années 1940. A l'exception peut-être de la Grèce, où la circulation du roman-feuilleton à partir des années 1840-1850 connaitra un succès remarquable auprès du public lettrée ${ }^{24}$, les sociétés balkaniques restent largement rurales jusqu'aux années 1940. Le passage de la culture populaire urbaine des années 1920-1940 à la culture de masse dans les années 1950-1960 n'est pas le même pour les pays du bloc soviétique et les pays du bloc occidental. L'évolution de l'industrie culturelle en Grèce et en Turquie nous offre une deuxième piste de recherche dans deux sociétés qui sont en train de se développer mais où les traditions en matière de mœurs restent très vives. Pour comprendre mieux le phénomène, une comparaison de la notion de culture de masse dans les pays communistes de la région et la redéfinition du terme "culture de masse " dans le contexte de la vie socialiste serait nécessaire pour une étape postérieure de la recherche. Une comparaison de la naissance de la culture de masse dans ces différents pays du Sud-Est pourrait conduire à une série de réflexions sur le sens à donner au terme ; une recherche plus élargie qui incorporerait les deux parties de l'Europe divisée pendant un demi-siècle serait également souhaitable et nous offre une piste de recherche à suivre. 


\section{NOTES}

1. Maurice Louis, Le Folklore et la danse, Paris, 1963, p.35 et M.P.Baumann «. Réflexions à propos de manifestations folkloriques ", Colloque International de. Folklore, Fribourg 1976, p.22. Voir également Alan Dundes, «Folklore as a Mirror of Culture » Elementary English, Vol. 46, No. 4 (april, 1969), p. 471-482. Pour une présentation plus détaille sur la définition de la culture populaire voir Holt N.Parker, "Toward a definition of popular culture», History and Theory 50 (may 2011), p. 147-150 et John Storay, Cultural Theory and Popular Culture, London, Pearson, 2001, p.1-16.

2. A titre d'exemple, en Grèce à partir de la fin du XIXe siècle, l'étude « des coutumes et des mœurs du peuple grec " devient quasi obligatoire pour les instituteurs et les philologues, professeurs de Lycée ou de l'Université d'Athènes dans les cadres de la «Laographie ». Sur la définition du terme et son exploitation idéologique voir Georges Prevelakis, " La Laographie grecque, ethnogéographie ou idéologie ? ", Géographie et cultures 2 (1992), p. 75-84.

3. Christian Taillard, «Diversité des définitions et différenciation des pratiques géographiques : contribution au débat sur la culture ", Espace géographique, 10.4, (1981), p. 263-264 et Yves Michaud , "Introduction » in Qu'est-ce que la culture ?, Odile Jacob, Paris 2001, p. 8-15. Pour une analyse de la notion « culture de masse » très utile fut l'article de Herbert Marcuse, « Remarks on a Redefinition of Culture ", in "Remarks on a Redefinition of Culture," in Gerald Holton (ed.), Science and Culture, Boston, Houghton Mifflin, 1965, p. 218-223. Voir également Jean-Yves Mollier, JeanFrançois Sirinelli et François Vallotton (dir.), Culture de masse et culture médiatique en Europe et dans les Amériques. 1860-1940, Paris, PUF, 2006 et Theodor Adorno, The culture industry, Routledge, New York 1991 et plus notamment p. 61-97.

4. Umberto Eco, De Superman au Surhomme, Grasset/Livre de Poche, Paris 1993, p. 113-145 et 163-207.

5. Voir l'article d'Hélène Antoniadis-Bibicou, « Conditions historiques de la formation du commun et du différent dans les cultures des pays balkaniques ", Études balkaniques, 3, 1996, p. 15-37 qui veut établir les points qui permettraient de définir une culture commune à l'ensemble des régions balkaniques, depuis l'Antiquité jusqu'à la Seconde Guerre mondiale. Dans le cas hellénique, cet effort consiste à « transformer la « réalité » hellénique en État indépendant et de construire une nouvelle identité nationale, à définir comme une unité continue de l'Antiquité classique à la période néo-hellénique contemporaine». Voir Irini Toundassaki et Roxani Caftantzoglou « Narrations de l'identité culturelle grecque. Les trois musées nationaux d'Athènes ", Ethnologie française, 2005/2 (Vol. 35), p. 229-242.

6. Pour une définition du terme voir Marc Angenot, "Qu'est-ce que la paralittérature ? ", Études

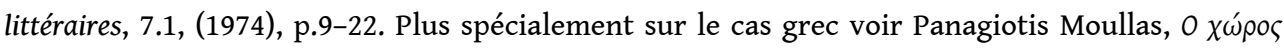

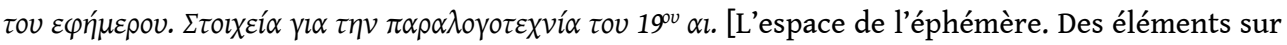
la paralittérature du XIXème s.], ed.Sokoli, Athènes 2007, p.21-24. Alexis Politis dans la synthèse

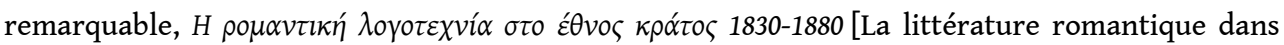
l'État-nation 1830-1880], Presses Univ. de Crète, 2017, analyse les influences du roman européen sur l'évolution littéraire du pays et l'apparition des éditions populaires à Athènes et dans la périphérie du monde hellénophone (Istanbul, Smyrne et Alexandrie).

7. Voir sur le roman de bandits en Grèce Christos Dermentzopoulos, «L'image du bandit dans le roman populaire qrec », Etudes Balkaniques (Cahiers Pierre Belon) No 7 (2000), p. 203-216.

8. Voir également Christos Dermentzopoulos-Lampros Flitouris, « Les aigles des montagnes : Des options du crime dans le roman populaire grec au début du XXème siècle », communication présentée au colloque international Fantômas en Europe. Les origines industrielles, sociales et esthétiques (fin XIXe-années 1930), Université de Limoges, 15-16-17 mai 2013. 


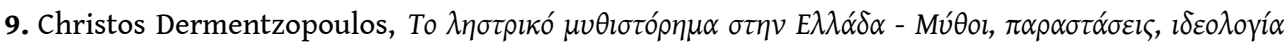
[Le roman de bandits en Grèce. Mythes, présentations, idéologie], Athènes, ed. Plethron, 1997, p. 79.

10. Ioannis Stefanidis, “Telling America's Story: US Propaganda Operations and Greek Public Reactions" Journal of the Hellenic Diaspora, 30.1 (2004), p. 39-95. Pour l'influence de la culture américaine voir Alexander Stephan (ed.); The Americanization of Europe: Culture, Diplomacy, and Anti-Americanism after 1945, Berghahn Books, New York, 2007.

11. Lampros Flitouris, "D'un modèle français" de diplomatie culturelle à l'invasion de l'american life'. Le cas grec d'après-guerre ", in R. Frank, A. Duplphy, M.A. Matard-Bonucci, P. Ory (dir.), Les relations internationales au vingtième siècle. De la diplomatie culturelle à l'acculturation, Peter Lang, Bruxelles, 2010, p. 149-162.

12. Loic Artiaga-Matthieu Letourneux, Fantômas! Biographie d'un criminel imaginaire, Paris, Les Prairies Ordinaires, 2013, p.157 et 168.

13. Skender Sherifi, "Regard sur la littérature albanaise », Confluences Méditerranéennes, $\mathrm{N}^{\circ} 14$ Printemps 1995, p. 163-167.

14. Sur les influences occidentales sur la littérature serbo-croate voir Milivoj Srebro (dir.), La Littérature serbe dans le contexte européen. Texte, Contexte et Intertextualité, MSHA, Pessac, 2013.

15. Pour une analyse de l'activité littéraire de la période de la fin des années 1940 voir Dajana Turkovic, "Death to all fascists! Liberty to the People" History and popular culture in Yugoslavia 1945-1990, MA thesis, Department of History, McGill University, Montreal, October, 2006, p. 39-45.

16. Turkovic, ibid, p. 51-52.

17. Le Croate Zvonimir Furtinger fut également le créateur d'un héros nommé Herlock Sholmes pour les adolescentes.

18. Voir Boris Kanzleiter et Krunoslav Stojaković. 1968 in Jugoslawien: Studentenproteste und kulturelle Avantgarde zwischen 1960 und 1975. Gespräche und Dokumente. Verlag J.H.W. Dietz, Bonn, 2008 et notamment la première partie, p. 9-43.

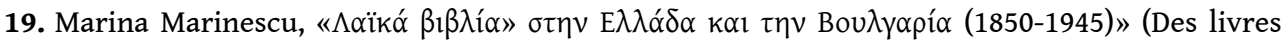
« populaires » en Grèce et en Bulgarie 1850-1945), Tetradia Ergasias 15 (1995), p.91-93.

20. Valentin Ivanov, "Bulgarian Science Fiction between the East and the West - II. Svetoslav Minkov and the Diabolic Fate of SF Writers Who Tried Their Hand" at Publishing", https:// worldsf.wordpress.com/2010/02/16/bulgarian-science-fiction-between-the-east-and-the-west-iisvetoslav-minkov-and-the-diabolic-fate-of-sf-writers-who-tried-their-hand-at-publishing/

$(13 / 5 / 2015)$

21. John Robert Colombo, "Science Fiction in Bulgaria", Science Fiction Studies, Vol. 8, No. 2 (Jul., 1981), p. 187-190.

22. Bogomil Raionov fut également un théoricien du roman noir et il a publié avec Georgi Asen Dzivgov en français l'essai Les rivages du réalisme (1970) et en bulgare Cherniyat roman [Le roman noir] (1970) et Masovata kultura [Culture de masse], (1974).

23. Andrei Gulyashki, The Zakhov Mission [Priklogyyeniyema na Avakum Zakhov (1963)], trad. Maurice Michael, Cassell Published, 1968.

24. Moullas, ibid, p.32-34. 


\section{RÉSUMÉS}

Le présent article fait partie d'une recherche en cours sur la transition des sociétés de l'Europe du Sud-Est : celle-ci se traduit par l'institutionnalisation de la culture folklorique ou populaire de la fin du XIXe siècle aux années 1940 pour la formation d'une culture nationale. Dans les pays balkaniques, la notion de culture de masse correspond à la transformation des sociétés après la guerre et notamment après les années 1950 et 1960. Pendant cette période, l'évolution de la culture populaire et la consommation de ses produits n'étaient pas les mêmes pour les sociétés de la région. De fait, l'examen d'une petite partie des productions des Balkans montre que la région étudiée ne partage pas les caractéristiques de l'Occident ni avant ni après les années 1940. A l'exception peut-être de la Grèce, où la circulation du roman-feuilleton à partir des années 1840-1850 connait un succès remarquable auprès du public lettré, les sociétés balkaniques restent largement rurales jusqu'aux années 1940. Le passage de la culture populaire urbaine des années 1920-1940 à la culture de masse dans les années 1950-1960 n'est pas le même pour les pays du bloc soviétique et les pays du bloc occidental. L'évolution de l'industrie culturelle en Grèce et en Turquie nous offre une deuxième piste de recherche dans deux sociétés qui sont en train de se développer mais où les traditions en matière de mœurs restent très vives.

\section{INDEX}

Keywords : Europe, Greece, Bulgaria, Yugoslavia, Turkey, media culture, popular literature, mass culture, 20th century

Mots-clés : Europe, Grèce, Bulgarie, Yougoslavie, Turquie, culture médiatique, littérature populaire, culture de masse, 20e siècle

\section{AUTEURS}

\section{LAMPROS FLITOURIS}

Lampros Flitouris est maître de conférences en histoire européenne à l'Univerisité de Ioannina.

\section{CHRISTOS DERMENTZOPOULOS}

Christos Dermentzopoulos est professeur en anthropologie d'art à l'Université de Ioannina. 